P25-CFQ

\title{
GRAPHENE QUANTUM DOTS SENSOR FOR THE DETERMINATION OF GRAPHENE OXIDE IN ENVIRONMENTAL WATER SAMPLES.
}

\author{
S. Benítez-Martínez ${ }^{\mathrm{a}}$, A.I. López-Lorente ${ }^{\mathrm{a}}$, M. Valcárcel ${ }^{\mathrm{a}}$. \\ ${ }^{a}$ Department of Analytical Chemistry, University of Córdoba. Annex C3 Building, Campus of Rabanales, \\ 14071 Córdoba. E-mail: qa1meobj@uco.es.
}

The growing production and use of graphene and graphene-family nanomaterials will increase the human and environmental exposure to such nanomaterials, being necessary to evaluate their possible effects in the environment and, subsequently, on the ecosystem health, including humans. Graphene oxide (GO) possesses an unique structure composed of $\mathrm{sp}^{2}$ carbons surrounded by $\mathrm{sp}^{3}$ carbons and oxygen containing functional groups ${ }^{1}$ which confer it an excellent aqueous solubility -hence their potential presence as contaminant of environmental waters-, surface functionalizability and fluorescence quenching ability.

In this work, fluorescent graphene quantum dots (GQDs) have been employed to develop a simple, fast and sensitive fluorescence-based sensor for the determination of GO in natural river water samples ${ }^{2}$. GO is retained in acetate of cellulose membranes for their preconcentration being subsequently recovered in a water solution by ultrasound irradiation. The interaction of graphene oxide with GQDs through hydrophobic $\pi-\pi$ stacking of the $G O$ with the aromatic network at the GQDs surface leads to a decrease -quenching- of the fluorescence of GQDs, which was employed as analytical signal for their quantification. The limit of detection obtained was $35 \mu \mathrm{g} \cdot \mathrm{L}^{-1}$ with a precision, for a $200 \mu \mathrm{g} \cdot \mathrm{L}^{-1}$ concentration of $\mathrm{GO}$ of $5.16 \%$.

The procedure has been applied for the determination of GO in environmental river water samples. In such case a clean-up step was necessary in order to remove the interfering organic matter. The filtration of a sodium hydroxide solution which eliminated the retained organic matter overcame such interference, being possible to quantify the presence of GO obtaining good values of recoveries, ranging from $83.7 \%$ to $108.2 \%$ depending on the concentration level.

In this work the two facets of Analytical Nanoscience and Nanotechnology -nanomaterials as analytical tools or objects- have been covered. GQDs are used as analytical tools owing to their exceptional fluorescence properties for the determination of GO in environmental samples.

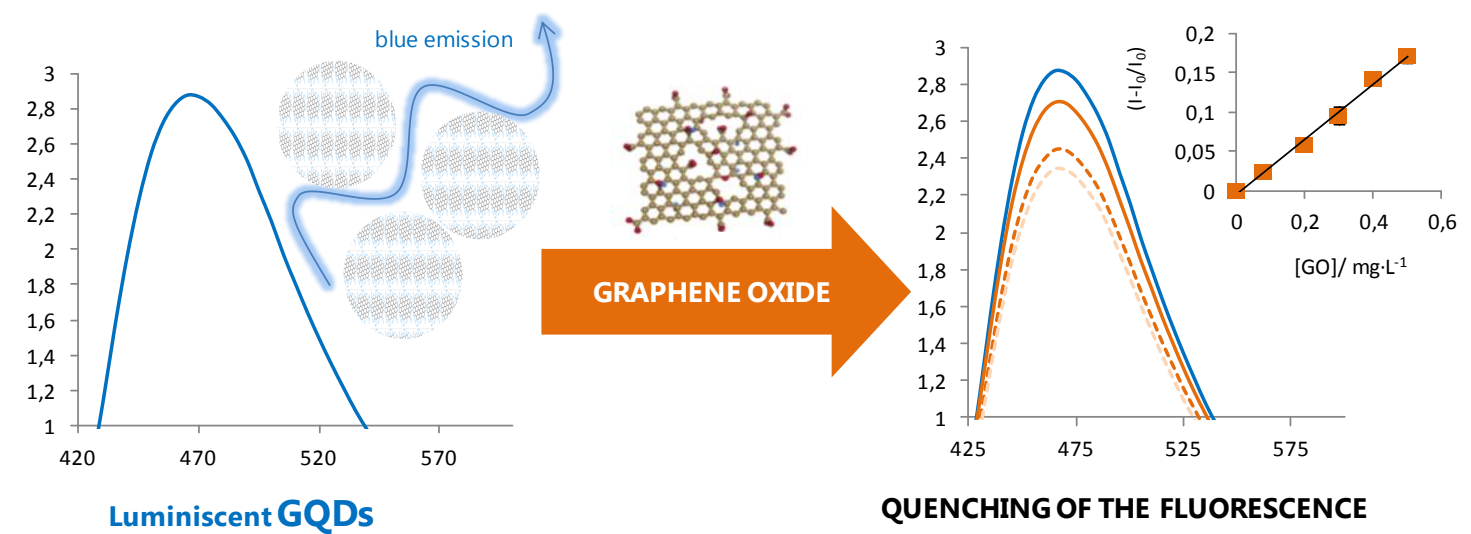

Figure 1. Scheme of the procedure developed for the determination of GO based on the quenching of the fluorescence of a GQDs solution upon mixing.

\footnotetext{
${ }^{1}$ Loh, K. P.; Bao, Q.; Eda, G.; Chhowalla, M. Nat. Chem., 2010, 2, 1015-1024.

${ }^{2}$ Benítez-Martínez, S.; López-Lorente, A.I.; Valcárcel, M.; Anal. Chem., 2014, 86, 12279-12284.
} 